\title{
Interest Rate Risk and the Forward Premium Anomaly in Foreign Exchange Markets
}

\author{
$\mathrm{Shu} \mathrm{Wu}$ \\ The University of Kansas*
}

This version: July 2005

\begin{abstract}
This paper shows that even adjusted for the time-varying risk premiums implied by the yield curves across countries, uncovered interest parity is still strongly rejected by the data. Moreover, factors that predict the excess bond returns are found not significant at all in predicting the foreign exchange returns. These results reject the joint restrictions on the exchange rate and interest rates imposed by dynamic term structure models, suggesting that foreign exchange markets and bond markets may not be fully integrated and we have to look beyond interest rate risk in order to understand the exchange rate anomaly.
\end{abstract}

JEL Classification: F31 G12

Keywords: forward premium puzzle, the term structure of interest rates

*Department of Economics, 213 Summerfield Hall, Lawrence, KS 66045. E-mail: shuwu@ku.edu. An earlier version of the paper was circulated under the title "On the Foreign Exchange Rate and the Term Structure of Interest Rates". I like to thank Davide Lombardo, Clemens Sialm, Tom Weiss and two anonymous referees for their helpful comments. Brandon Dupont provided excellent research assistance. Financial support from the New Faculty General Research Fund of the University of Kansas is gratefully acknowledged. 


\section{Introduction}

The forward premium anomaly in currency markets refers to the well documented empirical finding that the slope coefficient from the linear projection of the change in the foreign exchange rate on the interest rate differential between home and foreign countries is significantly negative, which implies that the domestic currency is expected to appreciate when domestic nominal interest rates exceed foreign interest rates. This is puzzling because economic intuition suggests that international investors would demand higher interest rates on currencies expected to fall in value. Among the explanations of this anomaly is that which interprets it as the evidence of time-varying risk premiums in currency markets. ${ }^{1}$ Fama (1984) shows that the implied risk premium and the expected depreciation must be negatively correlated and that the risk premium is more volatile than the expected change in the exchange rate.

Subsequent attempts to account for the exchange rate anomaly by timevarying risk premiums have mostly focused on exploring dynamic asset pricing models that can produce a risk premium with the requisite properties. These studies, among many others, include Engel and Frankel (1984) and Mark (1988) which apply the capital asset pricing model (CAPM) to currency prices. Hansen and Hodrick (1983) develop a latent factor asset pricing model to examine the risk premiums from investing in foreign currency deposits. Domowitz and Hakkio (1985) relate the risk premiums to conditional variances of exchange rates and interest rates. More recently, various versions of consumption-and-money-based dynamic asset pricing model of Lucas (1982) have been employed by Backus et al. (1993), Bekaert (1996) and Bekaert et al. (1997), Mark and Wu (1998) among many others. Engle (1996) provides an excellent survey of this literature and shows that most of the models are not able to generate large enough currency risk premiums that can account for the exchange rate anomaly.

The current paper takes on a less ambitious task. Instead of constructing a dynamic asset pricing model for the foreign exchange rate, it tries to

\footnotetext{
${ }^{1}$ Other explanations of the forward premium puzzle include irrational expectations, "peso problems", learning, etc. See papers discussed in Lewis (1995). Baillie and Bollerslev (2000) argues that the anomaly can be viewed as a statistical artifact due to small sample sizes and persistent autocorrelation in the forward premium. McCallum (1994) considers the influence of monetary policy. In this paper I focus on the role of time-varying risk premiums as in the term structure literature.
} 
identify possible risk factors underlying the exchange rate movement empirically. In particular, the paper investigates whether or not interest rate risk alone is responsible for the anomaly in foreign exchange markets.

The paper is partly motivated by a recent strand of research on the joint movements of the exchange rate and interest rates across countries based on dynamic term structure models. For example, Bansal (1997) documents some evidence of nonlinearity in the relation between the expected change of the foreign exchange rate and the home and foreign interest rate differential, and uses a single-factor term structure model to explain the exchange rate anomaly. Brandt and Santa-Clara (2002) estimate the joint dynamics of interest rates and foreign exchange rates using a version of the Cox, Ingersoll and Ross (1985) (henceforth CIR) model and find evidence of time-varying currency risk premiums. Backus et al. (2001) addresses the forward premium puzzle in the context of affine term structure models and shows that the models with interdependent factors offer the best hope of accounting for the properties of currency prices and interest rates. Also closely related to this literature is that of Lim and Ogaki (2003), which explores the theoretical implications of "indirect complementarity" between the short-term domestic and foreign bonds and develops a three-asset CAPM model under rational expectations. The model predicts a complicated relationship between the exchange rate and the term structure of interest rates. ${ }^{2}$

In these studies uncovered interest parity (henceforth UIP) doesn't hold due to time-varying risk premiums that are intimately related to the risk factors of the term structure of interest rates across countries. Using different parameterizations based on no-arbitrage condition, these studies then explore additional restrictions on the term structure models in order to account for the forward premium puzzle. The results from these studies suggest that the exchange rate movements could be reconciled with some particular term structure models allowing for rich dynamics of interest rates and the market price of risk in the bond markets.

The current paper looks for further evidence of the role of interest rate risk in explaining the currency market anomaly in the framework of dynamic term structure models. In particular, if risk premiums are time-varying, these models imply that factors predicting excess bond returns should also

\footnotetext{
${ }^{2}$ Other empirical studies that examine the joint dynamics of the term structure of interest rates and the exchange rate include Bekaert and Hodrick (2001), Byeon and Ogaki (1999). These studies, however, are not based on dynamic term structure models that impose no-arbitrage condition on bond prices across maturities.
} 
predict the foreign exchange returns. Moreover, uncovered interest rate parity should still hold if adjusted for the time-varying risk premiums implied by the yield curves across countries.

Using data of countries that form the major currency blocs, however, I find that both restrictions are strongly rejected. While forward interest rates are significant in predicting excess bond returns, they are found not significant at all in predicting the foreign exchange returns. Moreover, in the risk-premium-adjusted UIP regression based on the yield curves across countries, the slope coefficient on the interest rate differential is still found significantly negative in all cases examined in the paper.

These findings complement the results in Bekaert, Wei and Xing (2002), which examines jointly UIP and the Expectation Hypothesis of the Term Structure (EHTS) in a Vector Autoregression (VAR) model. They find that the statistical rejection of the EHTS is not an important determinant of the rejection of the UIP, suggesting that different risk factors may be present in the foreign exchange markets than those in the bond markets. We may have to look beyond interest rate risk in order to understand the anomaly in currency markets.

The rest of the paper is organized as follows. Section 2 outlines the general relationship between the exchange rate and the term structure of interest rates across countries. Section 3 discusses the data and presents the empirical results. Section 4 concludes.

\section{The foreign exchange rate and the term struc- ture of interest rates}

The key economic relationship underlying the empirical analysis below is that, under the assumption of no arbitrage in international bond markets,

$$
\log e_{t+1}-\log e_{t}=-\left(\log M_{t+1}-\log M_{t+1}^{*}\right)
$$

where $e_{t}$ is the domestic price of one unit of the foreign currency, $M_{t}$ and $M_{t}^{*}$ are the domestic and foreign stochastic discount factors (or pricing kernels) respectively. In various versions of consumption-and-money-based asset pricing model developed since Lucas (1982), $\log M_{t+1}$ or $\log M_{t+1}^{*}$ is simply the inflation-adjusted growth rate of marginal utility. This is the equation that plays the crucial role in the previous empirical studies of the 
joint dynamics of the exchange rate and interest rates based on dynamic term structure models. Other papers that also exploit this relation include Hollifield and Yaron (2000) and Brandt, Santa-Clara and Cochrane (2001), Iwata and $\mathrm{Wu}(2004)$ among others.

Intuitively, let $R_{t+1}$ be a vector of gross holding period return on domestic bonds of different maturities, absence of arbitrage in the bond market implies that there exists a positive stochastic discount factor $M_{t+1}$ such that (e.g. Harrison and Kreps, 1979)

$$
1=E_{t}\left(M_{t+1} R_{t+1}\right)
$$

where the expectation is taken with respect to information set at time $t$. Similarly, for a vector of holding period return on foreign bonds $R_{t+1}^{*}$, there exists a foreign discount factor $M_{t+1}^{*}$ such that

$$
1=E_{t}\left(M_{t+1}^{*} R_{t+1}^{*}\right)
$$

Now let $e_{t}$ by the domestic price of one unit of the foreign currency. For domestic investors who purchase the foreign bonds, absence of arbitrage implies that

$$
1=E_{t}\left[M_{t+1}\left(\frac{e_{t+1}}{e_{t}}\right) R_{t+1}^{*}\right]
$$

Under complete markets, $M_{t+1}$ and $M_{t+1}^{*}$ are unique. Therefore we must have

$$
\frac{e_{t+1}}{e_{t}}=\frac{M_{t+1}^{*}}{M_{t+1}}
$$

or, in terms of logarithms,

$$
\Delta \log e_{t+1}=-\left(\log M_{t+1}-\log M_{t+1}^{*}\right) .
$$

Note that if markets are incomplete, there will be multiple discount factors. The above relation doesn't hold for an arbitrary pair of discount factors as pointed out by Brandt et al. (2001). However, if interest rate alone spans the exchange risk, equation (6) would remain valid by choosing $M_{t+1}$ and $M_{t+1}^{*}$ to be the minimum-variance discount factors, i.e. the projection of the discount factors onto the space spanned by the bond returns.

For simplicity, I assume that $M_{t+1}$ and $M_{t+1}^{*}$ (as well as bond returns) are log-normally distributed conditional on information set at time $t$,

$$
M_{t+1}=e^{\mu_{t}-\lambda_{t}^{\prime} \varepsilon_{t+1}} \quad \text { and } \quad M_{t+1}^{*}=e^{\mu_{t}^{*}-\lambda_{t}^{*^{\prime}} \varepsilon_{t+1}^{*}}
$$


where $\mu_{t}$ and $\mu_{t}^{*}$ are scalars, and $\lambda_{t}$ and $\lambda_{t}^{*}$ are two vectors which are usually referred to as the market price of risk in the term structure literature. $\varepsilon_{t+1}$ and $\varepsilon_{t+1}^{*}$ are serially uncorrelated shocks distributed as $\mathcal{N}(\mathbf{0}, \mathbf{I})$. (Note that $\varepsilon_{t+1}$ and $\varepsilon_{t+1}^{*}$ can be contemporaneously correlated.)

Let $i_{t}$ and $i_{t}^{*}$ be the domestic and foreign continuously compounded riskfree short-term interest rate respectively. Using the fact $i_{t}=-\log \left(E_{t} M_{t+1}\right)$ and $i_{t}^{*}=-\log \left(E_{t} M_{t+1}^{*}\right)$, we can express $\mu_{t}$ and $\mu_{t}^{*}$ respectively as

$$
\mu_{t}=-\left(i_{t}+\frac{1}{2} \lambda_{t}^{\prime} \lambda_{t}\right) \quad \text { and } \quad \mu_{t}^{*}=-\left(i_{t}^{*}+\frac{1}{2} \lambda_{t}^{*^{\prime}} \lambda_{t}^{*}\right)
$$

which together with (6) we have ${ }^{3}$

$$
E_{t} \Delta \log e_{t+1}=\left(i_{t}-i_{t}^{*}\right)+\frac{1}{2}\left(\lambda_{t}^{\prime} \lambda_{t}-\lambda_{t}^{*^{\prime}} \lambda_{t}^{*}\right)
$$

If $M_{t+1}$ and $M_{t+1}^{*}$ are not $\log$-normally distributed, $E_{t} \Delta \log e_{t+1}$ would also depend on higher order conditional cumulants of the log pricing kernels in each country as shown in Backus et al (2001). The above equation can be viewed as the second order approximation. Moreover, since it is routinely assumed in the term structure literature that the market price of risk $\lambda_{t}$ and $\lambda_{t}^{*}$ are functions of some exogenous state variables and hence are time-varying, therefore it is not surprising from this perspective that UIP is rejected empirically. The term structure models can be used to explore the restrictions on the market price of risk $\left(\lambda_{t}\right.$ and $\left.\lambda_{t}^{*}\right)$ that can reconcile with the significantly negative slope coefficient typically found in a linear projection of the exchange rate movement $\Delta \log _{t+1}$ on the interest rate differential $i_{t}-i_{t}^{*}$.

In this paper, I instead examine two implications of the generalized UIP relation (9) without fully specifying the term structure models. In particular, let's express the gross bond returns as

$$
R_{t+1}=e^{E_{t} r_{t+1}+\sigma_{t} \varepsilon_{t+1}} \quad \text { and } \quad R_{t+1}^{*}=e^{E_{t} r_{t+1}^{*}+\sigma_{t}^{*} \varepsilon_{t+1}^{*}}
$$

where $r_{t+1}=\log R_{t+1}, r_{t+1}^{*}=\log R_{t+1}^{*}, \sigma_{t} \sigma_{t}^{\prime}$ and $\sigma_{t}^{*} \sigma_{t}^{*^{\prime}}$ are the conditional

\footnotetext{
${ }^{3}$ Dynamic term structure models are usually set up in continuous time. The appendix derives the continuous time analogue of equation (9).
} 
variance-covariance matrixes of the domestic and foreign bond returns respectively. It then follows from the no-arbitrage condition (2) and (3) that

$$
\begin{array}{r}
E_{t}\left(r_{t+1}-i_{t}\right)+\frac{1}{2} v_{t}=\sigma_{t} \lambda_{t} \\
E_{t}\left(r_{t+1}^{*}-i_{t}^{*}\right)+\frac{1}{2} v_{t}^{*}=\sigma_{t}^{*} \lambda_{t}^{*}
\end{array}
$$

where $v_{t}$ and $v_{t}^{*}$ are the diagonals of the variance matrixes $\sigma_{t} \sigma_{t}^{\prime}$ and $\sigma_{t}^{*} \sigma_{t}^{*^{\prime}}$ respectively. ${ }^{4}$ (11) and (12) are the standard asset pricing equations that express the risk premiums (plus an extra Jensen's inequality term due to taking logarithms) as the covariance of the bond returns and the stochastic discount factors. While the literature has used different specifications for $\lambda_{t}$ or $\lambda_{t}^{*}$ (no-arbitrage condition will impose additional cross-equation restrictions on the variance matrix), a common testable implication of the generalized UIP relation (9) and the bond pricing equations (11) and (12) is that factors driving the market price of risk and hence predicting excess bond returns $r_{t+1}-i_{t}$ or $r_{t+1}^{*}-i_{t}^{*}$ also predict the foreign exchange return $\Delta \log e_{t+1}-\left(i_{t}-i_{t}^{*}\right)$.

For example, within the widely used class of affine term structure models which nests Vasicek (1977) and CIR model (see Duffie and Kan, 1996, Dai and Singleton, 2000 and many others), $\lambda_{t}$ is assumed to be proportional to $\sqrt{a+b^{\prime} Y_{t}}$ where $Y_{t}$ is a vector of latent state variables following some diffusion process. ${ }^{5}$ This class of dynamic term structure models hence implies that $E_{t}\left[\Delta \log e_{t+1}-\left(i_{t}-i^{*}\right)\right]$ is a linear function of $Y_{t}$. On the other hand, the class of extended Gaussian term structure models has been used in Dai and Singleton (2002) and Ang and Piazzesi (2002), where $\lambda_{t}$ is assumed to be a linear function of $Y_{t}$ (homoscedasticity is usually assumed in this class of term structure models), a specification also shared by the model of Constantinides (1992) and the family of quadratic-Gaussian models of Ahn et al. (2002). These dynamic term structure models imply that $\lambda_{t}^{\prime} \lambda_{t}$ is a quadratic function of $Y_{t}$.

Another testable implication of (9) is that a risk-premium-adjusted UIP relation should still hold, i.e.

$$
E_{t} \Delta \log e_{t+1}-\frac{1}{2}\left(\lambda_{t}^{\prime} \lambda_{t}-\lambda_{t}^{*^{\prime}} \lambda_{t}^{*}\right)=i_{t}-i_{t}^{*}
$$

\footnotetext{
${ }^{4} r_{t+1}-i_{t}$ should be read as $r_{t+1}-i_{t} \cdot \mathbf{1}$ where $\mathbf{1}$ is a vector of 1 . The same notation is used throughout the paper.

${ }^{5}$ The volatilities of bond returns, $\sigma_{t}$ and $\sigma_{t}^{*}$, are shown to be proportional to $\sqrt{a+b^{\prime} Y_{t}}$ as well in this class of term structure models.
} 
Moreover, from (11) and (12), we have

$$
\begin{aligned}
& \lambda_{t}=\left(\sigma_{t}^{\prime} \sigma_{t}\right)^{-1} \sigma_{t}^{\prime}\left(E_{t}\left(r_{t+1}-i_{t}+\frac{1}{2} v_{t}\right)\right) \\
& \lambda_{t}^{*}=\left(\sigma_{t}^{*^{\prime}} \sigma_{t}^{*}\right)^{-1} \sigma_{t}^{*^{\prime}}\left(E_{t}\left(r_{t+1}^{*}-i_{t}^{*}+\frac{1}{2} v_{t}^{*}\right)\right)
\end{aligned}
$$

And using the fact that

$$
\begin{aligned}
& \operatorname{Var}_{t}\left(r_{t+1}-i_{t}+\frac{1}{2} v_{t}\right)=\sigma_{t} \sigma_{t}^{\prime} \\
& \operatorname{Var}_{t}\left(r_{t+1}^{*}-i_{t}^{*}+\frac{1}{2} v_{t}^{*}\right)=\sigma_{t}^{*} \sigma_{t}^{*^{\prime}}
\end{aligned}
$$

it's straight forward to show that

$$
\begin{aligned}
\lambda_{t}^{\prime} \lambda_{t} & =E_{t}\left(h_{t+1}^{\prime} h_{t+1}\right)-n \\
\lambda_{t}^{*^{\prime}} \lambda_{t}^{*} & =E_{t}\left(h_{t+1}^{*^{\prime}} h_{t+1}^{*}\right)-n^{*}
\end{aligned}
$$

where $h_{t+1}=\left(\sigma_{t}^{\prime} \sigma_{t}\right)^{-1} \sigma_{t}^{\prime}\left(r_{t+1}-i_{t}+\frac{1}{2} v_{t}\right), h_{t+1}^{*}=\left(\sigma_{t}^{*^{\prime}} \sigma_{t}^{*}\right)^{-1} \sigma_{t}^{*^{\prime}}\left(r_{t+1}^{*}-i_{t}^{*}+\right.$ $\left.\frac{1}{2} v_{t}^{*}\right)$, and $n$ and $n^{*}$ are the number of rows of $\sigma_{t}^{\prime} \sigma_{t}$ and $\sigma_{t}^{*^{\prime}} \sigma_{t}^{*}$ respectively. Therefore we can further express the risk-premium-adjusted UIP relation as

$$
E_{t}\left[\Delta \log e_{t+1}-\frac{1}{2}\left(h_{t+1}^{\prime} h_{t+1}-h_{t+1}^{*^{\prime}} h_{t+1}^{*}\right)\right]=\left(n^{*}-n\right)+i_{t}-i_{t}^{*}
$$

The above equation implies that after adjusting for a risk premium term that depends on the excess bond returns in the home and foreign countries, the exchange rate is expected to depreciate by the difference between the domestic and foreign interest short term interest rates. A linear projection of the right hand variable in (20) on the interest rate differential should still yield a slope coefficient of 1 .

\section{Results}

This paper focuses on countries that form the key currency blocs - the United States, Germany, Britain and Japan. ${ }^{6}$ Weekly data on spot exchange rates and Euro-currency interest rates for the above countries from January 1980 to December 1999 are taken from Datastream. The interest rates

\footnotetext{
${ }^{6}$ Bansal and Dahlquist (2000) presents evidence that the forward premium puzzle is confined to developed economies.
} 
include 7-day, 1-month, 3-month, 6-month and 12-month Euro-currency deposit rates.

The well documented forward premium puzzle comes from a linear regression of the following form

$$
\log e_{t+1}-\log e_{t}=\alpha+\beta\left(i_{t}-i_{t}^{*}\right)+\text { residual }
$$

where $e_{t}$ is the U.S. dollar price of 1 unit of a foreign currency at time $t$, $i_{t}$ and $i_{t}^{*}$ are the U.S. and the foreign interest rate between $t$ and $t+1$ respectively. A huge body of work has established that the estimate of the slope coefficient $\beta$ is significantly negative during the flexible exchange rate period (e.g. Hodrick, 1987, Bekaert and Hodrick, 1992 among many others), a puzzling result with the implication that the domestic currency is expected to appreciate when domestic nominal interest rates exceed foreign interest rates. Consistent with previous studies, I also find a negative estimate of $\beta$ ranging from -0.9729 to -2.2700 (Table 1 ).

If this exchange rate anomaly is due to the time-varying interest rate risks in the international bond markets, we should observe that factors predicting the excess bond returns also predict the foreign exchange return as shown in the previous section. To test this implication of the term structure models, continuously compounded holding period returns on 3-month, 6-month and 12-month Euro-currency deposits are constructed for the U.S., Germany, Britain and Japan respectively. The 1-week interest rate is used as an approximation to the risk-free short-term interest rate. Excess bond returns are obtained as the difference between the holding period returns and the short-term interest rate. Since it is well known from classic results in Fama and Bliss (1987) that forward interest rates can predict the excess bond returns, I regress the excess returns on 1-month, 3-month, 6-month and 12-month forward interest rates obtained from the weekly spot interest rates. $^{7}$ The results are reported in Table 2 .

We can see that the forward rates indeed forecast the excess bond returns. Across all four countries and different bond maturities, the regression shows that there are at least one or two forward rates that are significant in predicting the bond returns. For example, all four forward rates are shown to be significant in predicting the 6-month and 12-month bond returns in

\footnotetext{
${ }^{7}$ The forward rate at which investors contract at time $t$ to borrow and lend money starting at period $t+n$, to be paid back at period $t+n+1$ can be obtained as $f_{n, t}=$ $(n+1) y_{n+1, t}-n y_{n, t}$, where $y_{n+1, t}$ and $y_{n, t}$ are the $(n+1)$-period and $n$-period spot rates at time $t$ respectively.
} 
the U.S. In the case of Britain and Japan, the 1-month and 3-month forward rates are significant in predicting the 6-month and 12-month bond returns while the 3 -month returns are predicted by the 3 -month, 6 -month and 12-month forward rates. The forward rates seem to have the weakest forecasting power for the 12-month bond returns in the case of Germany as shown by the weak F-statistics. Nevertheless, the 1-month forward rate is still significant at $5 \%$ level in predicting the 12-month bond returns.

Turning to the foreign exchange rate, we can rewrite (9) as

$$
E_{t}\left[\Delta \log e_{t+1}-\left(i_{t}-i_{t}^{*}\right)\right]=\frac{1}{2}\left(\lambda_{t}^{\prime} \lambda_{t}-\lambda_{t}^{*^{\prime}} \lambda_{t}^{*}\right)
$$

The left hand side of (22) is the expected return from investing in the foreign currency. Under the affine term structure models, the right hand side of (22) will be a linear function of the factors that predict the domestic and foreign bond returns. Under the extended or quadratic Gaussian models, the right hand side of (22) will be a quadratic functions of the term structure factors. Hence to examine the predictability of the foreign exchange returns, I regress $\Delta \log e_{t+1}-\left(i_{t}-i_{t}^{*}\right)$ on the domestic and foreign forward interest rates and their squares. Table 3 reports the results for the three pairs of country where the U.S. is treated as the home country.

In sharp contrast to the case of bond returns, for all three exchange rates examined in the paper, none of the forward rates is significant in predicting the foreign exchange returns, violating the joint restrictions imposed on the foreign exchange rate and interest rates (see equation (22), (11) and (12)) by a wide range of dynamic term structure models. It is interesting to note that, since forward rates are used here as proxies of risk factors, hence proxies of the deviations from the EHTS, the result obtained in the current paper therefore is consistent with that in Bekaert et al (2002) which finds that the statistical rejection of the EHTS is not an important determination of the rejection of the UIP hypothesis.

Of course, the market price of risk could depend on the underlying factors in a way other than those suggested by the affine or Gaussian term structure models (e.g. Bansal, 1997). In these cases, the specification of $\lambda_{t}^{\prime} \lambda_{t}$ and $\lambda_{t}^{*^{\prime}} \lambda_{t}^{*}$ as quadratic functions of the forward rates may not be appropriate and can be only treated as an approximation. Nevertheless the risk-premiumadjusted UIP relation (20) allows us to further test the joint restrictions on the exchange rate and interest rates without making strong assumptions about the market price of risk. 
In particular, (20) implies that the foreign exchange rate is still expected to depreciate by the interest rate differential after adjusting for a risk premium term that depends on the excess bond returns in the home and foreign countries. To test this risk-premium-adjusted UIP relation, we need to estimate the conditional volatility of bond returns $\left(\sigma_{t}\right.$ and $\left.\sigma_{t}^{*}\right)$. Without loss of generality, let's consider the case where $\sigma_{t}$ and $\sigma_{t}^{*}$ are both square invertible matrixes of the same dimension. Under this assumption (20) can be simplified as

$$
\begin{aligned}
E_{t}\left[\Delta \log e_{t+1}\right. & -\frac{1}{2}\left(r_{t+1}-i_{t}+.5 v_{t}\right)^{\prime} \Omega_{t}^{-1}\left(r_{t+1}-i_{t}+.5 v_{t}\right) \\
& \left.+\frac{1}{2}\left(r_{t+1}^{*}-i_{t}^{*}+.5 v_{t}^{*}\right)^{\prime} \Omega_{t}^{*-1}\left(r_{t+1}^{*}-i_{t}^{*}+.5 v_{t}^{*}\right)\right]=i_{t}-i_{t}^{*}
\end{aligned}
$$

where $\Omega_{t}=\operatorname{Var}_{t}\left(r_{t+1}-i_{t}\right)$ and $\Omega_{t}^{*}=\operatorname{Var}_{t}\left(r_{t+1}^{*}-i_{t}^{*}\right)$, and $v_{t}$ and $v_{t}^{*}$ are the diagonals of the conditional variance matrixes $\Omega_{t}$ and $\Omega_{t}^{*}$ respectively.

The above relation between the exchange rate and interest rates is examined in two steps. First $\Omega_{t}$ and $\Omega_{t}^{*}$ are estimated using multivariate GARCH model and then the left-hand side of (23) is regressed on the constant term and the interest rate differential with $\Omega_{t}$ and $\Omega_{t}^{*}$ (as well as $v_{t}$ and $v_{t}^{*}$ ) being replaced by their respective estimates. ${ }^{8}$

The $\operatorname{GARCH}(1,1)$ estimates of the conditional variance matrix of the excess bond returns for the four countries are reported in Table 4. They are obtained as maximum likelihood estimates of variance matrix of the error term of Vector Autoregression (VAR) model of the excess bond return $r_{t+1}-i_{t}$ as follows (3-month, 6-month and 12-month bond returns are used in the estimation)

$$
r_{t+1}-i_{t}=\mu+\Phi(L)\left(r_{t}-i_{t-1}\right)+u_{t+1}
$$

where

$$
\begin{gathered}
E_{t} u_{t+1}=0, \quad E_{t}\left(u_{t+1} u_{t+1}^{\prime}\right)=\Omega_{t} \\
\Omega_{t}=\Gamma \Gamma^{\prime}+B \Omega_{t-1} B^{\prime}+A u_{t-1} u_{t-1}^{\prime} A^{\prime}
\end{gathered}
$$

\footnotetext{
${ }^{8}$ There has been a long strand of empirical literature that applies GARCH models to the short-term interest rates, including Anderson and Lund (1997) and Bali (2000) among many others. More recently, Zhou (2002) proposes a multi-factor GARCH model for the volatility of the forward rate and shows that the model is preferred over other volatility specifications. Christiansen (2002) estimates a multi-variate level-GARCH models for the long-term interest rates and the term spread.
} 
$\Gamma$ is a $3 \times 3$ lower triangular matrix, $B$ and $A$ are both $3 \times 3$ diagonal matrixes. The lag length of VAR is selected by the Hannan-Quinn information criterion.

From Table 4, we can see that all of the estimates of GARCH parameters are highly significant, indicating that stochastic volatility is an important feature of the bond returns. With the estimates of the conditional variance of the excess bond return $\hat{\Omega}_{t}$ and $\hat{\Omega}_{t}^{*}$, I then regress the change in the exchange rate $\Delta \log e_{t+1}$, adjusted for the estimated risk premiums, on the interest rate differential as suggested by (23). The results are reported in Table 5.

For the three country pairs examined in the paper, however, the exchange rate anomaly still exists. In fact, the slope coefficient on the interest rate differential not only remains significantly different from 1 , but also becomes even more negative in the risk-premium-adjusted UIP regression.

To further see the implications of the result, let $\hat{\beta}$ and $\tilde{\beta}$ denote the estimates of the slope coefficient in the standard and risk-premium-adjusted UIP regressions respectively, and let $\theta_{t}$ denote the risk premium term in equation (23). Since $\hat{\beta}=\operatorname{Cov}\left(\Delta \log e_{t+1}, i_{t}-i_{t}^{*}\right) / \operatorname{Var}\left(i_{t}-i_{t}^{*}\right)$, and $\tilde{\beta}=$ $\operatorname{Cov}\left(\Delta \log e_{t+1}-\theta_{t}, i_{t}-i_{t}^{*}\right) / \operatorname{Var}\left(i_{t}-i_{t}^{*}\right)$, the fact that $\tilde{\beta}<\hat{\beta}$ implies $\operatorname{Cov}\left(\theta_{t}, i_{t}-\right.$ $\left.i_{t}^{*}\right)>0$ (ignoring the estimation errors), i.e. the risk premium empirically extracted from bond returns is positively correlated with the interest rate differential, a result that is actually consistent with the specifications of many dynamic term structure models. For example, in the one-factor CIR model, the market price of risk $\left(\lambda_{t}\right.$ and $\left.\lambda_{t}^{*}\right)$ is proportional to the square root of the short-term interest rate $\left(\sqrt{i_{t}}\right.$ and $\left.\sqrt{i_{t}^{*}}\right)$, therefore $\theta_{t}$, which is equal to $\frac{1}{2}\left(\lambda_{t}^{2}-\lambda_{t}^{* 2}\right)$ (see equation (13)), will be positively correlated with the interest rate differential $i_{t}-i_{t}^{*}$.

One the other hand, if the time-varying risk premium $\theta_{t}$ were indeed the cause of the exchange rate anomaly, i.e. if $\Delta \log e_{t+1}=\theta_{t}+\left(i_{t}-i_{t}^{*}\right)+\varepsilon_{t+1}$ were true, the fact that the standard UIP regression produces a negative slope coefficient $(\hat{\beta}<0)$ implies $\operatorname{Cov}\left(\theta_{t}, i_{t}-i_{t}^{*}\right)<0$, i.e. the risk premium must be negatively correlated with the interest rate differential in order for it to account for the exchange rate anomaly.

In other words, the more negative estimate of the slope coefficient in the risk-premium-adjusted UIP regression reveals the tension between models of the foreign exchange rate and the term structure of interest rates. A time-varying-risk-premium-based model of the exchange rate requires that the risk premium is negatively correlated with the interest rate differential. 
The data on bond returns, however, indicate that the risk premium is actually positively correlated with the interest rate differential, a feature that is embedded in many dynamic term structure models. We have to either modify the model of the exchange rate or look beyond interest rate risk in order to understand the exchange rate anomaly.

As pointed by Fama (1984), a negative estimates of the slope coefficient in the standard UIP regression implies that the time-varying risk premiums from investing in foreign currencies, if exist, must be negatively correlated with the future depreciation of that currency and must be more volatile that the expected change in the exchange rate. To see that the foreign exchange risk-premiums recovered from the yield curves satisfy this "Fama criterion", Table 6 reports the correlation coefficient between the change in the exchange rate $\Delta \log e_{t+1}$ and the estimated risk premiums $\frac{1}{2}\left(\hat{\lambda}_{t}^{\prime} \hat{\lambda}_{t}-\right.$ $\left.\hat{\lambda}_{t}^{*^{\prime}} \hat{\lambda}_{t}^{*}\right)$ as well as their standard deviations. In all cases, the estimated risk premiums are indeed negatively correlated with the future depreciation of the foreign currencies and are much more volatile that the exchange rate movements. Figure 1 plots the estimated foreign exchange risk premiums for the three country pairs.

One caveat of the above risk-premium-adjusted UIP regression is that the no-arbitrage condition is not imposed in the GARCH estimation of the conditional variance of the excess bond returns. Imposing such condition would require full specification of the term structure model. A rejection of the riskpremium-adjusted UIP relation, however, could reflect mis-specification of the particular term structure model, not the violation of the fundamental relation between the exchange rate and interest rates across countries. ${ }^{9}$ Another problem of the above two-step approach is that estimation errors are introduced into the risk-premium-adjusted UIP regression. These estimation errors could be partly responsible for the more negative estimate of the slope coefficient in the risk-premium-adjusted UIP regression (notice that the estimates of $\Omega_{t}$ and $\Omega_{t}^{*}$ enter the left-hand side of equation (23) in a nonlinear way). But given that all of the GARCH parameters are estimated with very high precision (see Table 4 ), such distortion is unlikely to change the main results of the paper. ${ }^{10}$

\footnotetext{
${ }^{9}$ For example, both Duffee (2002) and Duarte (2004) find that the standard affine models with stochastic volatility have trouble simultaneously fitting some cross-sectional and time-series properties of the yield curve. Collin-Dufresne, Goldstein and Jones (2004) finds that interest rate volatility cannot be extracted from the cross-section of bond prices and proposes a term structure model with un-spanned stochastic volatility.

${ }^{10}$ To check that the results are robust to the estimation of the conditional variance, I
} 


\section{Concluding Remarks}

Dynamic term structure models based no-arbitrage condition admit flexible parameterizations of the market price of risk without specifying investor's utility function and have been very successful in modelling the joint movements of interest rates across maturities. ${ }^{11}$ For example, Dai and Singleton (2002) show the apparent failure of the expectation hypothesis of interest rates is not puzzling relative to a large class of dynamic term structure models. Since the change in the exchange rate is directly related to the difference between the domestic and foreign stochastic discount factors, it is therefore a natural extension to examine whether or not these models are also able to account for the joint dynamics of the exchange rate and interest rates across countries.

This paper finds evidence that reject the general restrictions on the exchange rate and interest rates imposed by the term structure models. It shows that while forward interest rates predict the excess bond returns across countries, they are not significant at all in predicting the foreign exchange returns. Moreover, the risk-premium-adjusted UIP based on the yield curves across countries is still rejected by the data. These findings imply that currency markets and bond markets may not be fully integrated, and there are risk factors orthogonal to the space of bond returns that are driving exchange rates. Interest rate risk alone can not account for the forward premium puzzle in the currency markets.

It is interesting to note that there have been empirical findings that UIP appears to hold better at longer horizons than at short, including Flood and Taylor (1997), Meredith and Chinn (1998) among others. The results of the current paper complement those findings and suggest that a model with segmented asset markets, such as the one in Alvarez, Atkeson and Kehoe (2002), may be necessary to bridge the gap between the empirical evidence and economic theories. Moreover, consistent with the theoretical implications of Lim and Ogaki and (2003), our results also indicate that there seems to exist a complicated nonlinear relationship between the exchange rate and the term structure of interest rates. This suggests that the complementary and substitution effects between domestic and foreign assets resulting from

also estimate $\Omega_{t}$ and $\Omega_{t}^{*}$ with the sample variance of rolling 12-week lagged VAR residuals. The slope coefficient in the risk-premium-adjusted UIP regression remains significantly negative.

${ }^{11}$ See Dai and Singleton (2003) for an excellent survey 
investor's optimization decision may also play an important role in determining the relation between the exchange rate and interest rates.

\section{References}

[1] Ahn, D. H., R. F. Dittmar and A. R. Gallant (2002) "Quadratic Gaussian models: theory and evidence", Review of Financial Studies 15, 243-288.

[2] Alvarez, F., A. Atkeson and P. Kehoe (2002) "Money, Interest Rates and Exchange Rates with Endogenously Segmented Markets", Journal of Political Economy 110, 73-112.

[3] Anderson, T. and J. Lund (1997) "Estimating ContinuoustimeStochastic Volatility Models of the Short-term Interest Rate", Journal of Econometrics 77, 343-377.

[4] Ang, A. and M. Piazzesi (2002) "A No-Arbitrage vector autoregression of term structure dynamics with macroeconomic and latent Variables", Journal of Monetary Economics 50, 745-787.

[5] Backus, D., A. Gregory and C. Telmer (1993) "Accounting for forward rates in markets for foreign currency", Journal of Finance 48, 18871908.

[6] Backus, D., S. Foresi and C. Telmer (2001) "Affine models of currency pricing: accounting for the forward premium anomaly", Journal of Finance 56, 279-304.

[7] Baillie, R. and T. Bollerslev (2000) "The forward premium anomaly is not as bad as you think", Journal of International Money and Finance 19, 471-488.

[8] Bali, T. G. (2000) "Modeling the Conditional Mean and Variance of the Short Rate Using Diffusion, GARCH and Moving Average Models", Journal of Future Market 20, 717-757.

[9] Bansal, R. (1997) "An exploration of the forward premium puzzle in currency markets", The Review of Financial Studies 10, 369-403.

[10] Bansal, R. and M. Dahlquist (2000) "The forward premium puzzle: different tales from developed and emerging economies", Journal of International Economics 51, 115-144. 
[11] Bekaert, G. (1996) "The Time-variation of risk and return in foreign exchange markets: A general equilibrium perspective", Review of Financial Studies 9, 427-470.

[12] Bekaert, G. and R. Hodrick (1992) "Characterizing predictable components in excess returns on equity and foreign exchange market", Journal of Finance 47, 467-509.

[13] Bekaert, G. and R. Hodrick (2001) "Expectation Hypothesis tests", Journal of Finance 56, 1357 - 1394.

[14] Bekaert, G., R. Hodrick and D. Marshall (1997) "The implications of first-order risk aversion for asset market risk premiums", Journal of Monetary Economics 40, 3-39.

[15] Bekaert, G., M. Wei and Y. Xing (2002) "Uncovered Interest Rate Parity and the Term Structure", NBER Working Paper No. 8759.

[16] Brandt, M. and P. Santa-Clara (2002) "Simulated likelihood estimation of diffusions with an application to exchange rate dynamics in incomplete markets", Journal of Financial Economics 63, 161-210.

[17] Brandt, M., P. Santa-Clara and J. H. Cochrane (2001) "International risk sharing is better than you think", NBER working paper 8404

[18] Byeon, Y. H. and M. Ogaki (1999) "A Empirical Investigation of Exchange Rates and the Term Structure of Interest Rates", Working paper, Ohio State University.

[19] Christiansen, C. (2002) "Multivariate Term Structure Model with Level and Heteroskedasticity Effects", Working Paper 129, Aarhus School of Business.

[20] Collin-Dufresne, P., R. Goldstein and C. Jones (2004) "Can Interest Rate Volatility Be Extracted from the Cross Section of Bond Prices? An Investigation of Un-spanned Stochastic Volatility", NBER Working Paper 10756.

[21] Constantinides, G. M. (1992) "A theory of the nominal term structure of interest rates", The Review of Financial Studies 5, 531-552.

[22] Cox, J., J. Ingersoll and S. Ross (1985) "A Theory of the term structure of interest rates", Econometrica 53, 385-407. 
[23] Dai, Q. and K. Singleton (2000) "Specification Analysis of Affine Term Structure Models", Journal of Finance 55, 1943-1978.

[24] Dai, Q. and K. Singleton (2002) "Expectation Puzzles, Time-varying Risk Premia, and Affine Models of the Term Structure", Journal of Financial Economics 63, 415-441.

[25] Dai, Q. and K. Singleton (2003) "Term Structure Dynamics in Theory and Reality", The Review of Financial Studies 16, 631-678

[26] Domowitz, I. and C. Hakkio (1985) "Conditional variance and the risk premium in the foreign exchange market", Journal of International Economics 19, 47-66.

[27] Duarte, J. (2004) "Evaluating an Alternative Risk Preference in Affine Term Structure Models", Review of Financial Studies 17, 379-404.

[28] Duffee, G. (2002) "Term Premia and Interest Rate Forecasts in Affine Models", Journal of Finance 57, 405-443.

[29] Duffie, D. and R. Kan (1996) "A yield-factor model of interest rates", Mathematical Finance 6, 379-406.

[30] Engle, C. (1996) "The forward discount anomaly and the risk premiums: A survey of recent evidence", Journal of Empirical Finance 3, 123-192.

[31] Engle, C. and J. A. Frankel (1984) "Do Asset Demand Functions Optimize over the Mean and Variance of Real Returns? A Six-Currency Test," Journal of International Economics 17, 309-323.

[32] Fama, E. F. (1984) "Forward and spot exchange rates", Journal of Monetary Economics 14, 319-38.

[33] Fama, E. F. and R. R. Bliss (1987) "The information in long-maturity forward rates", American Economic Review 77, 680-692.

[34] Flood, R. P. and M. P. Taylor (1997) "Exchange Rate Economics: What's Wrong with the Conventional Macro Approach?" in J. Frankel, G. Galli and A. Giovannini (editors) The Microstructure of Foreign Exchange Markets, University of Chicago Press.

[35] Hansen, L. and R. Hodrick (1983) "Risk averse speculation in the forward foreign exchange market", in J. A. Frenkel ed. Exchange Rates and International Macroeconomics, University of Chicago Press, 113-142. 
[36] Harrison, M. and D. Kreps (1979), "Martingales and arbitrage in multiperiod securities markets", Journal of Economic Theory 23, 381-408.

[37] Hodrick, R. (1987) The Empirical Evidence on the Efficiency of Forward and Futures Foreign Exchange Markets, New York: Harwood Academic Publishers.

[38] Hollifield, H. and A. Yaron (2000) "The Foreign Exchange Risk Premium: Real and Nominal Factors", Working paper, The University of Pennsylvanian.

[39] Iwata, S. and S. Wu (2004) "What Macroeconomic Risks Are (not) Shared by International Investors?" Journal of Money, Credit and Banking, forthcoming.

[40] Lewis. L (1995) "Puzzles in international financial markets", in Grossman. G and Gogoff K. edt. Handbook of International Economics 3, 1913-1974.

[41] Lim, H. S. and M. Ogaki (2003) "A Theory of the Exchange Rate and the Term Structure of Interest Rates", Rochester Center for Economic Research Working paper No. 504.

[42] McCallum, B. T. (1994) "A reconsideration of the uncovered interest rate parity relationship", Journal of Monetary Economics 33, 105-132.

[43] Mark, N. (1988) "Time varying betas and risk premia in the pricing of forward foreign exchange contracts", Journal of Financial Economics $22,335-354$.

[44] Mark, N. and Y. Wu (1998) "Understanding Spot and Forward Exchange Rate Regressions", Journal of Applied Econometrics 12, 715734 .

[45] Meredith, G. and M. Chinn (1998) "Long-horizon Uncovered Interest Parity", NBER working paper No.6797.

[46] Vasicek, O. (1977) "An Equilibrium Characterization of the Term Structure", Journal of Financial Economics 5, 177-188.

[47] Zhou, A. (2002) "Modeling the Volatility of the Heath-Jorrow-Morton Model: A Multifactor GARCH Analysis", Journal of Empirical Finance $9,35-56$. 


\section{Appendix The exchange rate and the term struc- ture in continuous time}

Let $P_{t}$ be a $N \times 1$ vector of domestic bond prices described by the following stochastic differential equations: ${ }^{12}$

$$
\frac{d P_{t}}{P_{t}}=\mu_{t} d t+\sigma_{t} d W t
$$

where $\sigma_{t}$ is a $N \times M$ matrix and $W_{t}$ is a $M \times 1$ vector of standard Brownian motions. Absence of arbitrage in the bond market implies that there exists a state price deflator $\pi_{t}$ such that $P_{t} \pi_{t}$ is a martingale under some technical conditions [see Duffie (1996)]. Hence for a bond maturing at $t+\tau$, its price $p_{t}$ is given by

$$
p_{t} \equiv e^{-\tau r_{t, \tau}}=E_{t}\left(\frac{\pi_{t+\tau}}{\pi_{t}}\right)
$$

where $r_{t, \tau}$ is the $\tau$-period interest rate. Moreover, the martingale result also implies that $\pi_{t}$ satisfies

$$
\frac{d \pi_{t}}{\pi_{t}}=-i_{t} d t-\lambda_{t}^{\prime} d W_{t}
$$

and

$$
\sigma_{t} \lambda_{t}=\mu_{t}-i_{t} \cdot \mathbf{1}
$$

where $i_{t}$ is the instantaneous short term interest rate, $\lambda_{t}$ is a $M \times 1$ vector of the market price of risk and $\mathbf{1}$ is a $N \times 1$ vector of 1 .

From (27), we have ${ }^{13}$

$$
\pi_{t+\tau}=\pi_{t} e^{-\int_{t}^{t+\tau}\left(i_{s}+\frac{1}{2} \lambda_{s}^{2}\right) d s-\int_{t}^{t+\tau} \lambda_{s}^{\prime} d W_{s}}
$$

Note that similar results also hold for the foreign variables, i.e. for a vector of foreign bonds whose prices are described by

$$
\frac{d P_{t}^{*}}{P_{t}^{*}}=\mu_{t}^{*} d t+\sigma_{t}^{*} d W_{t}^{*}
$$

\footnotetext{
$12 \frac{d P_{t}}{P_{t}}$ should be read as $\left(\frac{d P_{1 t}}{P_{1, t}}, \frac{d P_{2, t}}{P_{2, t}}, \cdots, \frac{d P_{N, t}}{P_{N, t}}\right)^{\prime}$. The same notation is used below.

${ }^{13}$ To simplify notation, $\lambda^{2}$ is used to denote $\lambda^{\prime} \lambda$ below.
} 
we have that the price of a bond maturing at $t+\tau$ is given by

$$
p_{t}^{*} \equiv e^{-\tau r_{t, \tau}^{*}}=E_{t}\left(\frac{\pi_{t+\tau}^{*}}{\pi_{t}^{*}}\right)
$$

where

$$
\pi_{t+\tau}^{*}=\pi_{t}^{*} e^{-\int_{t}^{t+\tau}\left(i_{s}^{*}+\frac{1}{2}\left(\lambda_{s}^{*}\right)^{2}\right) d s-\int_{t}^{t+\tau} \lambda_{s}^{*^{\prime}} d W_{s}^{*}}
$$

and

$$
\sigma_{t}^{*} \lambda_{t}^{*}=\mu_{t}^{*}-i_{t}^{*} \cdot \mathbf{1}
$$

To see how exchange rate is related to the term structure, let $e_{t}$ be the dollar price of one unit of the foreign currency. Absence of arbitrage then implies that

$$
e_{t} p_{t}^{*}=E_{t}\left(\frac{\pi_{t+\tau}}{\pi_{t}} e_{t+\tau}\right)
$$

or

$$
p_{t}^{*}=E_{t}\left(\frac{\pi_{t+\tau}}{\pi_{t}} \frac{e_{t+\tau}}{e_{t}}\right)
$$

Since

$$
p_{t}^{*}=E_{t}\left(\frac{\pi_{t+\tau}^{*}}{\pi_{t}^{*}}\right)
$$

we can define

$$
\pi_{t}^{*}=\pi_{t} e_{t}
$$

Therefore

$$
\frac{e_{t+\tau}}{e_{t}}=\frac{\pi_{t+\tau}^{*}}{\pi_{t}^{*}} \frac{\pi_{t}}{\pi_{t+\tau}}
$$

Using (29) and (32), we get

$$
\begin{aligned}
\log e_{t+\tau}-\log e_{t} & =\int_{t}^{t+\tau}\left(i_{s}-i_{s}^{*}\right) d s+\frac{1}{2} \int_{t}^{t+\tau}\left(\lambda_{s}^{2}-\left(\lambda_{s}^{*}\right)^{2}\right) d s \\
& +\int_{t}^{t+\tau} \lambda_{s}^{\prime} d W_{s}-\int_{t}^{t+\tau} \lambda_{s}^{*^{\prime}} d^{*} W_{s}
\end{aligned}
$$


Note that the last two terms are martingale, hence we have

$$
E_{t}\left(\log e_{t+\tau}-\log e_{t}\right)=E_{t}\left(\int_{t}^{t+\tau}\left(i_{s}-i_{s}^{*}\right) d s\right)+\frac{1}{2} E_{t}\left(\int_{t}^{t+\tau}\left(\lambda_{s}^{2}-\left(\lambda_{s}^{*}\right)^{2}\right) d s\right)
$$

Let $\tau=1$ and if the time interval $(t, t+1)$ is very small, the above equation can be well approximated by

$$
E_{t}\left(\log e_{t+1}-\log e_{t}\right)=i_{t}-i_{t}^{*}+\frac{1}{2}\left(\lambda_{t}^{\prime} \lambda_{t}-\lambda_{t}^{*^{\prime}} \lambda_{t}^{*}\right)
$$


Table 1: The forward premium puzzle 1980-1999

\begin{tabular}{c||c|c|c}
\hline Exchange Rate & $\hat{\alpha}$ & $\hat{\beta}$ & $R^{2}$ \\
\hline US Dollar/German Mark & 0.0100 & -0.9729 & 0.0016 \\
& $(0.0297)$ & $(0.9358)$ & \\
\hline US Dollar/British Pound & $-0.0651^{* *}$ & $-2.2120^{* *}$ & 0.0066 \\
& $(0.0281)$ & $(0.9830)$ & \\
\hline US Dollar/Japanese Yen & $0.1129^{* *}$ & $-2.2700^{* *}$ & 0.0068 \\
& $(0.0345)$ & $(0.8642)$ & \\
\hline
\end{tabular}

Note: The estimates are obtained from the OLS regression of the annualized weekly depreciation of the U.S. dollar, $\Delta \log e_{t+1}$, on the constant term and the interest rate differential $i_{t}-i_{t}^{*}$. $i_{t}$ and $i_{t}^{*}$ are continuously compounded 1-week U.S. and foreign interest rates (annualized). The regressions are done at weekly frequency from 1980 to 1999. Numbers in parenthesis are the heteroscedasticity and autocorrelation consistent standard errors. ** means the estimate is significant at 5\% level. 
Table 2: Predicting excess bond returns 1980-1999

\begin{tabular}{c||c|c|c|c|c|c}
\hline The U.S. & $c$ & $f_{1, t}$ & $f_{3, t}$ & $f_{6, t}$ & $f_{12, t}$ & F-stat \\
\hline 3-month bond & 0.0006 & -0.3369 & -0.9157 & $3.6047^{* *}$ & $-2.3439^{* *}$ & 15.2587 \\
& $(0.0043)$ & $(0.4282)$ & $(0.6193)$ & $(1.0125)$ & $(0.9143)$ & \\
\hline 6-month bond & 0.0120 & $-2.5913^{* *}$ & $2.6013^{*}$ & $4.5968^{* *}$ & $-4.75741^{* *}$ & 16.9456 \\
& $(0.0083)$ & $(0.8945)$ & $(1.4013)$ & $(1.8649)$ & $(1.4400)$ & \\
\hline 12-month bond & $-0.0337^{* *}$ & $2.9284^{* *}$ & $-4.1316^{*}$ & $6.1580^{* *}$ & $-4.4821^{* *}$ & 7.02384 \\
& $(0.0153)$ & $(1.4210)$ & $(2.1734)$ & $(2.6258)$ & $(1.9117)$ & \\
\hline Germany & $c$ & $f_{1, t}$ & $f_{3, t}$ & $f_{6, t}$ & $f_{12, t}$ & F-stat \\
\hline 3-month bond & 0.0016 & -0.3667 & -0.2216 & $1.3770^{* *}$ & $-0.8053^{*}$ & 4.71646 \\
& $(0.0020)$ & $(0.2891)$ & $(0.3386)$ & $(0.5954)$ & $(0.4391)$ & \\
\hline 6-month bond & $0.0111^{* *}$ & $-3.8308^{* *}$ & $6.0824^{* *}$ & -1.5824 & -0.8798 & 25.1602 \\
& $(0.0045)$ & $(0.8665)$ & $(1.3090)$ & $(1.3039)$ & $(0.8734)$ & \\
\hline 12-month bond & -0.0131 & $2.1584^{* *}$ & -1.2526 & -2.2002 & 1.59387 & 1.89775 \\
& $(0.0086)$ & $(1.1026)$ & $(1.3588)$ & $(1.8071)$ & $(1.3776)$ & \\
\hline Britain & $c$ & $f_{1, t}$ & $f_{3, t}$ & $f_{6, t}$ & $f_{12, t}$ & F-stat \\
\hline 3-month bond & 0.0028 & 0.3694 & $-2.1938^{* *}$ & $2.6828^{* *}$ & $-0.8996^{* *}$ & 7.3747 \\
& $(0.0038)$ & $(0.3848)$ & $(0.6394)$ & $(0.6987)$ & $(0.4600)$ & \\
\hline 6-month bond & $0.0224^{* *}$ & $-2.9272^{* *}$ & $3.5958^{* *}$ & -0.9811 & 0.0258 & 4.53563 \\
& $(0.0079)$ & $(0.7845)$ & $(1.2820)$ & $(1.4362)$ & $(0.9549)$ & \\
\hline 12-month bond & -0.0220 & $2.9428^{* *}$ & $-4.5174^{* *}$ & -0.5104 & 2.3424 & 2.64454 \\
& $(0.0141)$ & $(1.2405)$ & $(1.7979)$ & $(2.5402)$ & $(1.7763)$ & \\
\hline Japan & $c$ & $f_{1, t}$ & $f_{3, t}$ & $f_{6, t}$ & $f_{12, t}$ & F-stat \\
\hline 3-month bond & 0.0014 & -0.3535 & $-1.3614^{* *}$ & $2.3927^{* *}$ & $-0.7090^{* *}$ & 17.5715 \\
& $(0.0012)$ & $(0.3494)$ & $(0.5303)$ & $(0.4537)$ & $(0.2416)$ & \\
\hline 6-month bond & 0.0039 & $-3.5284^{* *}$ & $6.0062^{* *}$ & -1.6655 & -0.8114 & 30.1128 \\
& $(0.0023)$ & $(0.7335)$ & $(1.1578)$ & $(1.1330)$ & $(0.6000)$ & \\
\hline 12-month bond & $-0.0089^{*}$ & $5.5689^{* *}$ & $-4.2303^{*}$ & -2.0979 & 1.0931 & 10.4521 \\
& $(0.0054)$ & $(1.6726)$ & $(2.5231)$ & $(2.7116)$ & $(1.2236)$ & \\
\hline
\end{tabular}

Note: This table reports the results from OLS regressions of excess bond returns on forward interest rates. The explanatory variables include a constant term $c$, 1-month forward rate $f_{1, t}, 3$-month forward rate $f_{3, t}, 6$-month forward rate $f_{6, t}$ and 12-month forward rate $f_{12, t}$ obtained from the weekly spot rates. Numbers in parenthesis are heteroscedasticity and autocorrelation consistent standard errors. F-statistics are reported in the last column. ** means the coefficient is significant at $5 \%$ level, ${ }^{*}$ means the coefficient is significant at $10 \%$ level. 
Table 3: Predicting the foreign exchange returns 1980-1999

\begin{tabular}{c||cc|cc|cc}
\hline \multicolumn{1}{c||}{} & \multicolumn{2}{c|}{ US/Germany } & US/UK & \multicolumn{3}{c}{ US/Japan } \\
\hline$c$ & -0.6693 & $(0.3463)$ & 0.1897 & $(0.3892)$ & -0.0398 & $(0.2707)$ \\
$f_{1, t}$ & 12.3095 & $(21.7126)$ & 26.8504 & $(23.5934)$ & 1.8090 & $(22.6315)$ \\
$f_{3, t}$ & 17.4260 & $(30.4380)$ & 5.1081 & $(28.4668)$ & 16.6674 & $(32.1376)$ \\
$f_{6, t}$ & -39.6515 & $(31.5160)$ & -24.6262 & $(30.0511)$ & -12.1863 & $(27.1126)$ \\
$f_{12, t}$ & 20.1658 & $(22.1279)$ & 5.5571 & $(20.0792)$ & -4.2688 & $(17.0486)$ \\
$f_{1, t}^{2}$ & -116.91 & $(109.004)$ & -112.906 & $(119.254)$ & -30.8306 & $(104.607)$ \\
$f_{3, t}^{2}$ & -26.5225 & $(125.788)$ & -52.0745 & $(129.748)$ & -67.9968 & $(130.971)$ \\
$f_{6, t}^{2}$ & 177.714 & $(139.202)$ & 124.963 & $(135.906)$ & 42.9288 & $(112.956)$ \\
$f_{12, t}^{2}$ & -116.167 & $(99.5883)$ & -48.225 & $(87.6251)$ & 17.0791 & $(66.8771)$ \\
$f_{1, t}^{*}$ & 35.8324 & $(31.2068)$ & -46.3088 & $(37.9702)$ & -10.8436 & $(25.0845)$ \\
$f_{3, t}^{*}$ & -50.6073 & $(33.0568)$ & 57.5349 & $(49.6176)$ & -10.1622 & $(22.9696)$ \\
$f_{6, t}^{*}$ & 29.5496 & $(42.6977)$ & -8.66863 & $(56.4235)$ & 30.9635 & $(22.6228)$ \\
$f_{12, t}^{*}$ & -4.36618 & $(31.5725)$ & -17.6294 & $(35.4312)$ & -8.49268 & $(21.0079)$ \\
$f_{1, t}^{* 2}$ & -199.664 & $(224.541)$ & 142.922 & $(212.46)$ & 147.127 & $(158.137)$ \\
$f_{3, t}^{* 2}$ & 269.571 & $(201.417)$ & -224.131 & $(265.336)$ & -136.089 & $(180.907)$ \\
$f_{6, t}^{* 2}$ & -137.632 & $(263.632)$ & 174.738 & $(263.072)$ & 7.45358 & $(173.217)$ \\
$f_{12, t}^{* 2}$ & 11.2313 & $(203.687)$ & -13.4345 & $(149.703)$ & 6.99439 & $(126.834)$ \\
\hline F-Statistics & 1.3719 & & 2.3051 & & 1.7789 & \\
\hline
\end{tabular}

This table reports the results from regressing the foreign exchange returns $\Delta \log e_{t+1}$ on the domestic and foreign forward interest rates and their squares. The explanatory variables include a constant term $c$, the U.S. and the foreign forward rate $f_{i, t}, f_{i, t}^{*}$ and their squares $f_{i, t}^{2}, f_{i, t}^{* 2}$ for $i=1,3,6,12$. The forward rates are obtained from the weekly spot rates. Numbers in parenthesis are the heteroscedasticity and autocorrelation consistent standard errors. 
Table 4: Variance of bond returns 1980-1999

\begin{tabular}{c||c|c|c|c}
\hline & the U.S. & Germany & Britain & Japan \\
\hline$\Gamma_{11}$ & 0.0035 & 0.0058 & 0.0038 & 0.0037 \\
& $(0.0002)$ & $(0.0002)$ & $(0.0002)$ & $(0.0001)$ \\
\hline$\Gamma_{21}$ & 0.0057 & 0.0076 & 0.0095 & 0.0062 \\
& $(0.0004)$ & $(0.0005)$ & $(0.0005)$ & $(0.0004)$ \\
\hline$\Gamma_{22}$ & 0.0043 & 0.0053 & 0.0032 & 0.0037 \\
& $(0.0002)$ & $(0.0003)$ & $(0.0003)$ & $(0.0002)$ \\
\hline$\Gamma_{31}$ & 0.0106 & 0.0133 & 0.0165 & 0.0095 \\
& $(0.0012)$ & $(0.0010)$ & $(0.0013)$ & $(0.0008)$ \\
\hline$\Gamma_{32}$ & 0.0043 & 0.0086 & 0.0080 & 0.0053 \\
& $(0.0008)$ & $(0.0008)$ & $(0.0009)$ & $(0.0006)$ \\
\hline$\Gamma_{33}$ & 0.0073 & 0.0093 & 0.0068 & 0.0062 \\
& $(0.0007)$ & $(0.0007)$ & $(0.0007)$ & $(0.0006)$ \\
\hline$B_{11}$ & 0.9414 & 0.8560 & 0.9438 & 0.9466 \\
& $(0.0034)$ & $(0.0072)$ & $(0.0017)$ & $(0.0034)$ \\
\hline$B_{22}$ & 0.9541 & 0.8834 & 0.9361 & 0.9376 \\
& $(0.0024)$ & $(0.0049)$ & $(0.0026)$ & $(0.0033)$ \\
\hline$B_{33}$ & 0.9688 & 0.9100 & 0.9477 & 0.9278 \\
& $(0.0025)$ & $(0.0054)$ & $(0.0029)$ & $(0.0030)$ \\
\hline$A_{11}$ & 0.2936 & 0.4640 & 0.3292 & 0.2698 \\
& $(0.0099)$ & $(0.011)$ & $(0.0076)$ & $(0.0116)$ \\
\hline$A_{22}$ & 0.2536 & 0.4294 & 0.3268 & 0.3130 \\
& $(0.0091)$ & $(0.0078)$ & $(0.0071)$ & $(0.0097)$ \\
\hline$A_{33}$ & 0.2000 & 0.3454 & 0.2787 & 0.3664 \\
& $(0.010)$ & $(0.011)$ & $(0.0081)$ & $(0.0088)$ \\
\hline
\end{tabular}

Note: this table reports the estimates of the conditional variance of the excess bond returns in the U.S., Germany, Britain and Japan respectively. The conditional variance is assumed to be characterized by $\operatorname{GARCH}(1,1)$ specification: $\Omega_{t}=\Gamma \Gamma^{\prime}+B \Omega_{t-1} B^{\prime}+A u_{t-1} u_{t-1}^{\prime} A^{\prime}$ where $\Gamma$ is a $3 \times 3$ lower triangular matrix, $B$ and $A$ are both $3 \times 3$ diagonal matrixes. $\Gamma_{i j}, B_{i j}$ and $A_{i j}$ in the table represent the $(i, j)$ element of $\Gamma, A$ and $B$ respectively. Numbers in parenthesis are the heteroscedasticity and autocorrelation consistent standard errors. 
Table 5: The risk-premium-adjusted UIP 1980-1999

\begin{tabular}{c||c|c|c}
\hline Exchange Rate & $\hat{\alpha}$ & $\hat{\beta}$ & $R^{2}$ \\
\hline US Dollar/German Mark & 0.2048 & $-10.3386^{* *}$ & 0.0029 \\
& $(0.1785)$ & $(5.0818)$ & \\
\hline US Dollar/British Pound & -0.0903 & $-11.3496^{*}$ & 0.0025 \\
& $(0.2417)$ & $(7.0034)$ & \\
\hline US Dollar/Japanese Yen & $0.5434^{* *}$ & $-11.2112^{* *}$ & 0.0028 \\
& $(0.2208)$ & $(5.6331)$ & \\
\hline
\end{tabular}

Note: this table reports the OLS estimates of the risk-premium-adjusted UIP regression of (23). The dependent variable is $\Delta \log e_{t+1}-\frac{1}{2}\left[\left(r_{t+1}-\right.\right.$ $\left.\left.i_{t}+.5 \hat{v}_{t}\right)^{\prime} \hat{\Omega}_{t}\left(r_{t+1}-i_{t}+.5 \hat{v}_{t}\right)-\left(r_{t+1}^{*}-i_{t}^{*}+.5 \hat{v}_{t}^{*}\right)^{\prime} \hat{\Omega}_{t}^{*}\left(r_{t+1}^{*}-i_{t}^{*}+.5 \hat{v}_{t}^{*}\right)\right] . \quad \hat{\alpha}$ is the coefficient on the constant term, $\hat{\beta}$ is the coefficient on the interest rate differential $i_{t}-i_{t}^{*}$. Numbers in parenthesis are the heteroscedasticity and autocorrelation consistent standard errors. ${ }^{* *}$ means the coefficient is significant at $5 \%$ level. ${ }^{*}$ means the coefficient is significant at $10 \%$ level.

Table 6: Risk premiums and the exchange rate 1980-1999

\begin{tabular}{c||c|c|c}
\hline & German Mark & British Pound & Japanese Yen \\
\hline $\operatorname{Corr}\left[-\Delta \log e_{t+1}, \frac{1}{2}\left(\hat{\lambda}_{t}^{\prime} \hat{\lambda}_{t}-\hat{\lambda}_{t}^{*^{\prime}} \hat{\lambda}_{t}^{*}\right)\right]$ & -0.0159 & -0.0448 & -0.0162 \\
$\operatorname{Std}\left(\Delta \log e_{t+1}\right)$ & 0.7904 & 0.7831 & 0.8241 \\
$\operatorname{Std}\left[\frac{1}{2}\left(\hat{\lambda}_{t}^{\prime} \hat{\lambda}_{t}-\hat{\lambda}_{t}^{*^{\prime}} \hat{\lambda}_{t}^{*}\right)\right]$ & 5.3394 & 5.4582 & 5.3437 \\
\hline
\end{tabular}

Note: this table reports the correlation coefficient between the change in the exchange rate and the estimated risk premiums from the yield curves across countries $\operatorname{Corr}\left[-\Delta \log e_{t+1}, \frac{1}{2}\left(\hat{\lambda}_{t}^{\prime} \hat{\lambda}_{t}-\hat{\lambda}_{t}^{*} \hat{\lambda}_{t}^{*}\right)\right]$ as well as the standard deviations of the exchange rate $\operatorname{Std}\left(\Delta \log e_{t+1}\right)$ and the risk premiums $\operatorname{Std}\left[\frac{1}{2}\left(\hat{\lambda}_{t}^{\prime} \hat{\lambda}_{t}-\hat{\lambda}_{t}^{*} \hat{\lambda}_{t}^{*}\right)\right]$. 
Figure 1: Estimated Foreign Exchange Risk Premiums
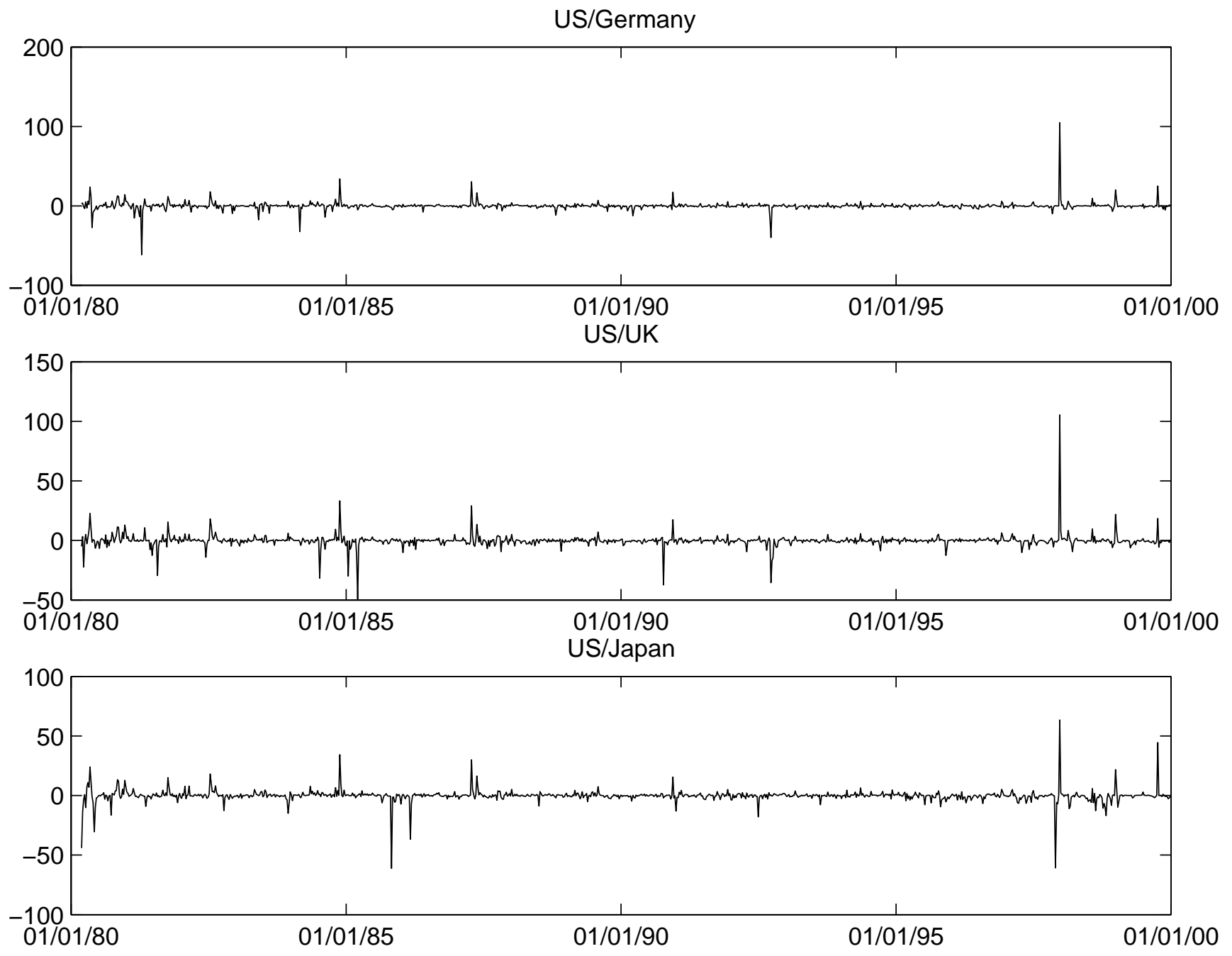